\title{
Toxicological Effect of Monosodium Glutamate in Seasonings on Human Health
}

\author{
Augustine I Airaodion ${ }^{1 *}$, Emmanuel 0 Ogbuagu' ${ }^{2}$, Etinosa U Osemwowa ${ }^{3}$, Uloaku Ogbuagu ${ }^{1}$, Chimdi E \\ Esonu ${ }^{1}$, Aanu P Agunbiade ${ }^{1}$, Davidson Okereke $^{1}$ and Abiodun P Oloruntoba ${ }^{1}$
}

${ }^{1}$ Department of Biochemistry, Federal University of Technology, Nigeria

${ }^{2}$ Department of Pharmacology and Therapeutics, Abia State University, Nigeria

${ }^{3}$ Department of Food Chain and Health, University of Helsinki, Finland

*Corresponding author: Augustine I Airaodion, Department of Biochemistry, Federal University of Technology, Nigeria.
Received Date: May 01, 2019

Published Date: May 16, 2019

\section{Abstract}

The use of seasonings to enhance the flavor of food has been on the increase in recent time. Different types of seasonings are produced daily. The constituent of these flavor-enhancers is unknown to ignorant consumers. They only want to eat food with good taste without consideration of the effect of these additives on their health. These seasonings contain monosodium glutamate (MSG) which really spiced the food. This review focuses on the toxicological effect of monosodium glutamate in seasonings on human health. MSG was found to induce oxidative stress, renal and hepatotoxicity. It increased total protein and cholesterol. It also induces fibroid. MSG increases the number of platelets, bleeding time and clotting time. It adversely perturbed some sex hormones: testosterone, Estrogen and progesterone. It also leads to increase in body weight and thus obesity. However, these effects can be minimized by the consumption of garlic, ginger, and turmeric. Consumption of food rich in vitamins $\mathrm{C}$ and $\mathrm{E}$ and other antioxidants can also minimize the effect of MSG on human health. Locust bean has been reported to be a good alternative to seasonings containing MSG.

Keywords: Monosodium glutamate; Seasoning; Free radicals; Toxicological effect; Human health

\section{Introduction}<smiles>N[C@@H](CCC(=O)O)C(=O)O</smiles>

Figure 1: Structure of Glutamate.

Monosodium glutamate (MSG) is a sodium salt of glutamic acid. It is usually a white powder. Water ionizes it into free sodium ions and glutamic acid, which is an organic compound consisting of five carbon atoms. It has a carboxylic $(-\mathrm{COOH})$ group and an amino $\left(-\mathrm{NH}_{2}\right)$ group attached to an "alpha" carbon atom (a carbon atom joined directly to the - $\mathrm{COOH}$ group) (David, 2008). It is an alpha amino acid. The molecular formula of MSG is $\mathrm{C}_{3} \mathrm{H}_{8} \mathrm{NNaO}_{4}$ and its molecular mass is 169.11 gmol-1. MSG has the same basic structure of amino acids, with an amine group $\left(-\mathrm{NH}_{2}\right)$ and carboxylate ion instead of the carboxylic group (-COO-). MSG has almost same structure with glutamate. The difference is that one hydrogen atom at the carboxylic chain has been replaced with a sodium atom, hence, the name monosodium glutamate [1] (Figure 1\&2).

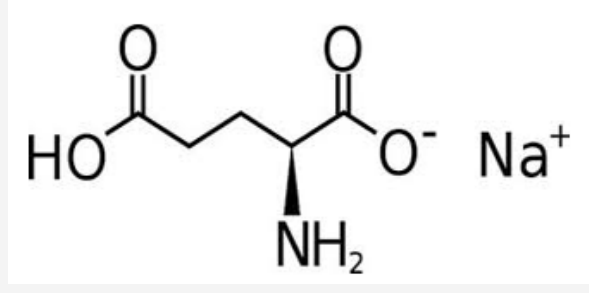

Figure 2: Structure of Monosodium Glutamate.

Monosodium glutamate has a distinctive taste that falls outside the region of the four classic tastes: sweet, sour, salty, and bitter. This taste is called "Umami," also referred to as "Xien Wei" in 
Chinese or "savory, "broth-like" or "meaty taste" in English. Due to this special taste, many food producers use MSG to enhance the flavor of their product [2]. Recently, Chaudhari et al. [3] identified a specific glutamate taste receptor on the tongue. Three umami substances (glutamate, 5-inosinate, and 5-guanylate) were found by Japanese scientists, but umami has not been recognized in Europe and America for a long time. In the late 1900s, umami was internationally recognized as the fifth basic taste based on psychophysical, electrophysiological, and biochemical studies. Three umami receptors (T1R1+T1R3, mGluR4, and mGluR1) were identified. There is a synergism between glutamate and the 5-nucleotides. Among the above receptors, only T1R1+T1R3 receptor exhibits the synergism [4]. Since glutamate and 5-inosinate are contained in various foods, umami tasted is induced by the synergism in daily eating [4].

The safety and toxicity of MSG had become controversial in the last few years because of reports of adverse reactions in people who have eaten foods that contain MSG. Many studies had confirmed the adverse reactions of MSG [1,5,6]. MSG has been reported to cause headache, vomiting, diarrhea, irritable bowel syndrome, asthma attacks in asthmatic patients and panic attacks [1]. Obuchi et al. [6] studied the effect of garlic extracts on MSG induced fibroid in wistar rats and reported that MSG alone increased total protein, cholesterol and estradiol (estrogen), which in turn, induced fibroid in the rats. However, treatment with garlic extracts near-completely abrogated/mitigated any effects that have been induced by MSG alone.

Egbuonu et al. [7] reported a study aimed at investigating the potentials of low concentration administration of monosodium glutamate in inducing hepatotoxicity in male albino rats. In that study, it was observed that treating rats with monosodium glutamate at a low concentration $(5 \mathrm{mg} / \mathrm{kg}$ of body weight) could be hepatotoxic without significant cholestasis or pathologies of the bone. Onyema et al. [8] reported that MSG at a dose of $0.6 \mathrm{mg} / \mathrm{g}$ body weight induced the oxidative stress and hepatotoxicity in rats and vitamin E ameliorated MSG-induced oxidative stress and hepatotoxicity. Meraiyebu et al. [9] reported that MSG increased the number of platelets, bleeding time and clotting time in MSGtreated rats. Onyema et al. [10] tested the hypothesis that alteration in glucose metabolism following MSG administration might be a contributor to the changes in the markers of oxidative stress observed in the animals. The pattern of induction of oxidative stress and alteration of glucose metabolic enzymes in the animals was an indication that oxidative stress induced by MSG in the renal tissues of rats might be contributed by increased tissue glucose concentration resulting from enhanced renal gluconeogenesis [10]. Nwajei et al. [11] reported that four selected food seasonings (labeled IS, KC, SMC and BS) commonly consumed in Nigeria adversely perturbed some sex hormones: testosterone, Estrogen and progesterone of wistar albino rats due to the presence of MSG in these seasonings. Kolawole [12] investigated the effect of orally administered MSG on food consumption, body weight and some biochemical and hematological parameters in adult wistar rats and reported that MSG at the doses or $5-15 \mathrm{mg} / \mathrm{kg}$ body weight was not hazardous to health.

\section{Production of MSG}

The Chinese have used certain seaweeds to enhance the flavor of food for some 2000 years. In 1908, the flavor enhancing agent was identified as glutamic acid [1]. Shortly thereafter, methods for extracting glutamic acid from seaweeds were developed [1]. MSG is manufactured through a process of protein hydrolysis, where glutamic acid is freed from protein through enzymatic fermentation or use of chemicals. MSG is also manufactured by a fermentation process in which bacteria are grown aerobically in a liquid nutrient medium. The bacteria release glutamic acid as a by-product of metabolism into the liquid nutrient medium in which they are grown. The glutamic acid is then separated from the fermentation broth by filtration, concentration, acidification and crystallization and conversion to its sodium salt.

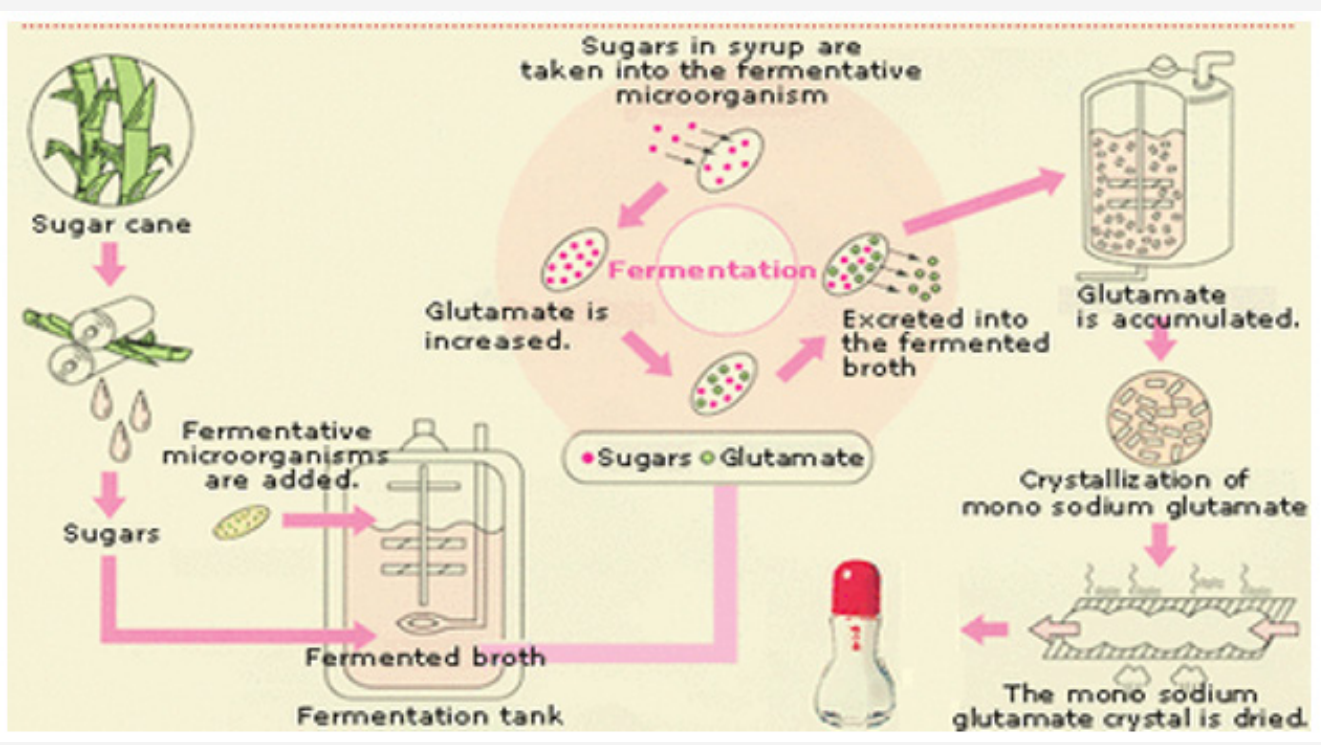

Figure 3: Industrial Production of Monosodium Glutamate by Fermentation. 
The name "monosodium glutamate" refers to a 99\% pure combination of glutamic acid and sodium [13]. About 1.9 million tons of monosodium g1utamate are produced worldwide per year by fermentation using Corynebacterium glutamicum or related species [13]. These bacteria are biotin auxotrophs and biotin (vitamin $\mathrm{B}_{7}$ ) is used as a cofactor. Producers prefer the use of sugars to produce MSG. Some sugar sources used includes, sugarcane, starch hydrolysates gotten from corn or cassava tubers, among others. Ammonia and ammonium salts are added as Nitrogen source. Vitamins and other nutrients are added to finish off the process. Glutamate accumulation in the medium occurs only under biotin-limiting condition. The requirements for biotin limitation prevented the use of standard raw materials such as sugar molasses because they contained biotin. Addition of penicillin, or the use of microorganisms auxotrophic for glycerol or oleate, that allows the bacteria to produce large amounts of glutamate without biotin limitation (Figure 3).

\section{Impurities Found in MSG}

Monosodium glutamate contains D-glutamic acid, pyroglutamic acid, and various other contaminants in addition to L-glutamic acid [2].

\section{D-Glutamate}

Every amino acid (except glycine) can occur in two isomeric forms, because of the possibility of forming two different enantiomers around the central carbon atom. By convention, these are called L- and D-forms, analogous to lefthanded and righthanded configurations. Only L-amino acids are manufactured in the cells and incorporated into proteins. Some D-amino acids are found in the cell walls of bacteria, but not in bacteria proteins. Glutamate has both the D- and L- enantiomers and only the L-glutamate enantiomer has flavor enhancing properties [14]. Manufactured monosodium glutamate contains over $99.6 \%$ of the naturally predominant L-glutamate form, which is a higher proportion of free glutamate ions of fermented naturally occurring foods. Fermented products such as soy sauce steak sauce and Worcestershire sauce have levels of glutamate like foods with added monosodium glutamate. However, $5 \%$ or more of the glutamate may be D-enantiomer. Nonfermented naturally occurring foods have lower relative levels of D-glutamate than fermented products [14] (Figure 4).

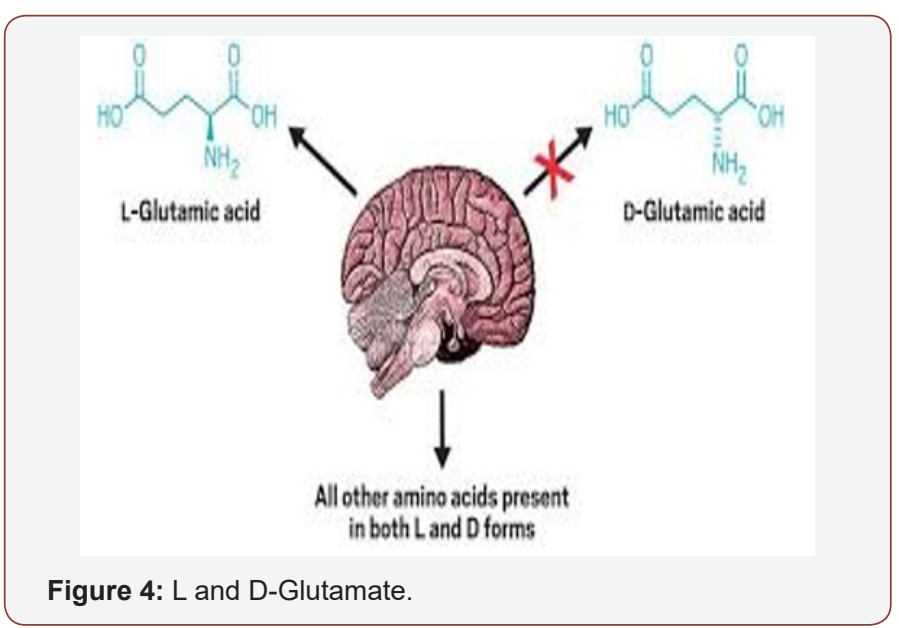

Unlike other D-amino acids, D-glutamate is not oxidized by the D-amino acid oxidases; therefore, the detoxification pathway is not available for handling D-glutamate. Likewise, D- glutamate when ingested, largely escapes most deamination reactions (unlike its L-counterpart). Free D-glutamate is found in mammalian tissue at surprisingly high levels, with D-glutamate accounting for $9 \%$ of the total glutamate present in the Liver. D-glutamate is the most potent natural inhibitor of glutathione synthesis identified to date and this may account for its localization to the liver, since circulating D-glutamate may alter redox stability [14].

\section{Pyroglutamic acid}

Pyroglutamic acid (PCA) is also known as 5-oxoproline, pidolic acid, or pyroglutamate. It is a common but rarely studied natural amino acid derivative in which free amino group of glutamic acid or glutamine cyclizes to form a lactem. It is a metabolite in the glutathione cycle that is converted to glutamate by 5-oxoprolinase. Pyroglutamate is found in many proteins including bacteriorhodopsin. N-terminal glutamic acid and glutamine residue can spontaneously cyclize to become pyroglutamate or enzymatically converted by glutaminyl cyclases. Pyroglutamate is a heterocyclic compound and is present in plasma of several species including humans. However, local brain injections of very high concentrations of pyroglutamate induced neurotoxic lesions that appeared to be like those produced by kianic acid [15] (Figure 5).

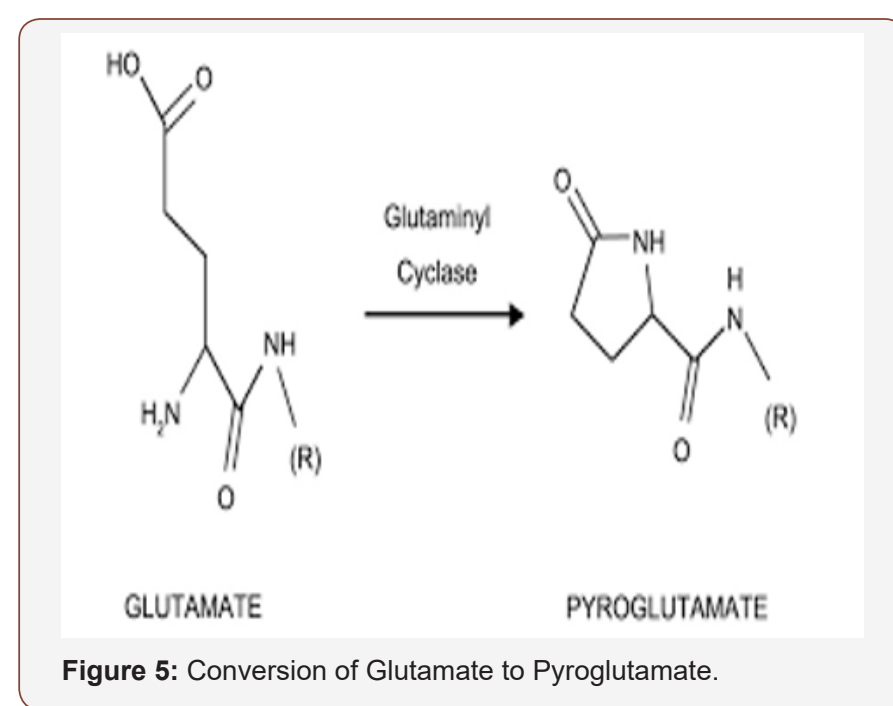

Pyroglutamic acid has also been found to be produced by glutamate in the presence of $\gamma$-GCS, glutamine synthetase and glutamate-5-kinase enzymes [16-18]. The enzyme-bound phosphorylated glutamate is the intermediate in all three enzymatic reactions. Activated glutamate is transferred to an acceptor molecule, namely cysteine, ammonia and NADPH respectively. Phosphorylated or activated glutamate is highly unstable and prone to spontaneous cyclization into pyroglutamic acid [19]. If the acceptor molecule is not present or unavailable, spontaneous cyclization of activated glutamate leads to pyroglutamic acid generation. $\gamma$-GCS which catalyzes the first step of glutathione biosynthesis activates glutamate that may be converted into pyroglutamic acid in the absence of cysteine [17]. Similarly, in 
methanotrophs, it has been proposed that in stress and nitrogenlimiting conditions pyroglutamic acid is generated from glutamate via glutamine synthetase, as found in in vitro conditions [20].

\section{Mono and dichloro propanols}

3-monochloropropane-1,2-diol (3-MCPD) is an organic chemical compound which is the most common member of chemical food contaminants known as chloropropanols. It is suspected to be carcinogenic in humans. It is primarily created in foods during protein hydrolysis when hydrochloric acid is added at high temperature to speed up the breakdown of proteins into amino acids. As a byproduct of this process, chloride can react with the glycerol backbone of lipids to produce 3-MCPD. In 2000, a survey of soy sauces and similar products available in the UK was carried out by the Joint Ministry of Agriculture, Fisheries and Food/Department of Health Food Safety and Standards Group (JFSSG) and reported more than half of the samples collected from retail outlets contained various levels of 3-MCPD [21]. In 2001, the United Kingdom Food Standards Agency (FSA) found in tests of various oyster sauces and soy sauces that $22 \%$ of samples contained 3-MCPD at levels considerably higher than those deemed safe by the European Union. About two-thirds of these samples also contained a second chloropropanol called 1,3-dichloropropane2-ol (1,3-DCP) which experts advise should not be present at any levels in food. Both chemicals have the potential to cause cancer and the Agency recommended that the affected products be withdrawn from shelves and avoided [22] (Figure 6\&7).

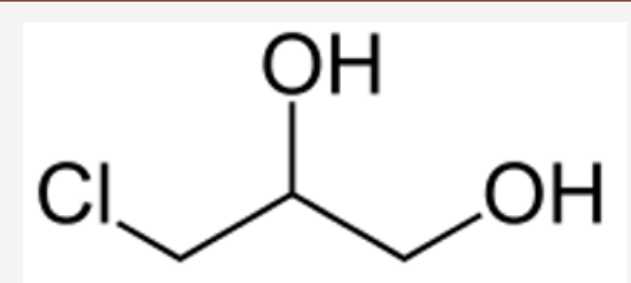

Figure 6: Monochloro Propan-1,2-diol.

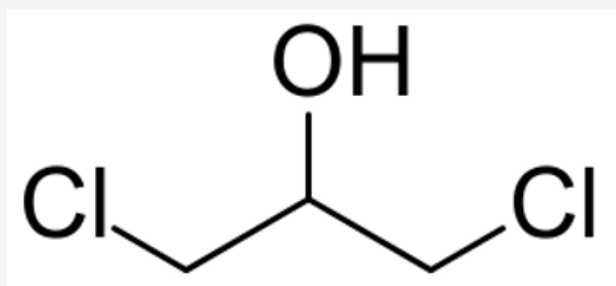

Figure 7: 1,3-Dichloro Propan-2-ol.

\section{MSG in Seasoning Cubes}

Food seasoning is a substance that adds flavor to food, for example salt, peppers, and other spices. Spices are vegetable substances of indigenous or exotic origin which are aromatic and have hot piquant tastes, used to enhance the flavor of foods or to add to them the stimulant ingredient contained in them [22]. Seasonings can also be used to replace common salt in a great variety of other industrially prepared food items as well as in the preparation of foods both in restaurants, catering, home kitchen etc. Such seasonings are particularly suitable for soups, beefs, and other foods in which salty, and/or spiced seasonings are used. The ingredient mixture and seasonings when added to various food items change the food composition [23].

There are several brands of food seasonings readily available in the open markets, in-street shops and supermarkets. These include: Star maggi, knorr, royco, doyin, jumbo (cubes), Onga, Mixpy, Benny, Aluba shrimp seasoning (powdered), A-one, Vedan, Ajino-moto, Salsa and Tasty (monosodium glutamate). Reports have indicated that the major active ingredients in flavor enhancers are salt $(\mathrm{NaCl})$ and monosodium glutamate (MSG). Other ingredients include: Hydrogenated palm oil, Caramel, Colour, Soyabeans, locust beans, Maltodextrin, Corn starch, Chicken fat, Disodium guanylate, Disodium inosilate, Hydrolyzed plant/Vegetable, protein, Tomatoes, Natural spices etc. [24].

\section{Chinese Restaurant Syndrome}

The "Chinese restaurant syndrome "(CRS) was first described over 40 years ago. The original description of the symptoms having their onset about 20 minutes after the meal included numbness or burning at the back of the neck, radiating into both arms and sometimes into the anterior thorax, which was associated with a feeling of general weakness and palpitation [25]. The symptoms of flushing, dizziness, syncope, and facial pressure were described later [26]. Children can react with fever, convulsion or a steady anxiety. Monosodium glutamate was widely believed to be associated with CRS. However, reviews of relevant studies have proposed that the studies which associated MSG with CRS did not have the robust experimental design, results were inconsistent and the frequency of responses to MSG intake was not high enough to bring evidence that MSG is the trigger of CRS [27]. CRS is said to occur in people who are sensitive to MSG.

This issue remains controversial. Since MSG is identical to glutamate naturally contained in many foods, it is absorbed and metabolized by the body in the same manner. On the other hand, damaging effects have been associated with ingesting MSG, such as those related to Alzheimer and Parkinson diseases. This was dismissed by a consensus conference lead by Nobel Preis laureate Professor Dr. Konrad Beyreuther, because MSG ingested through food cannot cross the blood-brain-barrier in healthy persons [28].

\section{Metabolism of Dietary Glutamate}

Glutamate is the main constituent of dietary protein and is also consumed in many foods as an additive in the form of monosodium glutamate. Evidence from human and animal studies suggests that glutamate is a major oxidative fuel for the gut and that dietary glutamate is extensively mobilized in the first pass by the intestine [29]. Glutamate is also an important precursor for bioactive molecules, including glutathione, and functions as a key neurotransmitter. Several studies have shown that glutamate is extensively metabolized in the intestine [29-31]. Glutamate is the main excitatory neurotransmitter in the body and multiple glutamate receptors and transporters have been found in the 
gastrointestinal tract and enteric nervous system [32]. Recent studies have also shown that two vesicular glutamate transporters (VGLUTs), VGLUTs1 and VGLUTs2, are present in enteric nervous and pancreatic tissue $[28,32]$. It has become apparent that the gut particularly the intestine is also a major site of catabolism of several amino acids, mainly nonessential amino acids glutamine, glutamate, and aspartate [29].

An important distinction to be made, however, although amino acids are catabolized in both liver and gut tissues, the extent to which they are completely oxidized to carbon dioxide varies [29]. Glutamate is a key amino acid linking hepatic amino acid catabolism and gluconeogenesis, because many amino acids are first catabolized to glutamate by transamination [29]. The intestinal metabolism of glutamate is presumed to occur largely in epithelial cells lining the mucosa, enterocytes (Figure 8).

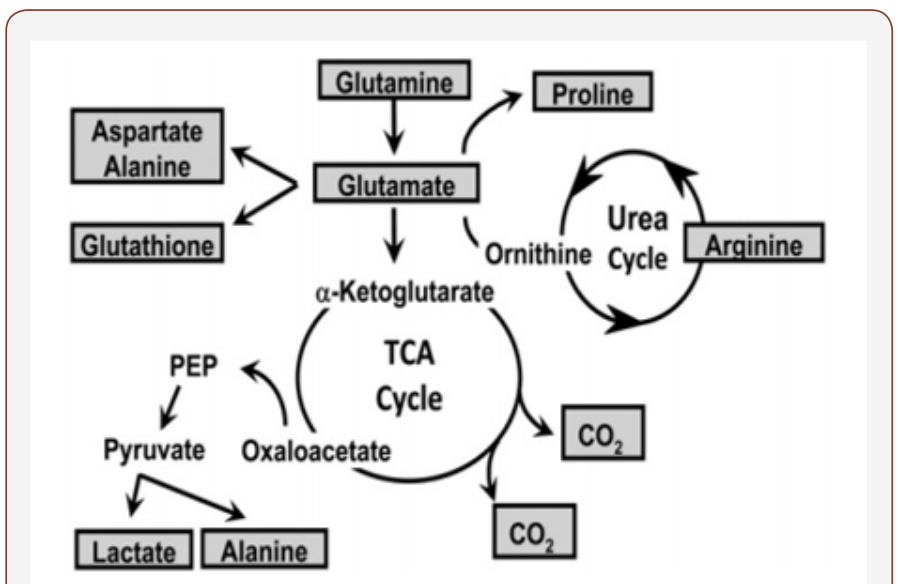

Figure 8: Metabolic fates of dietary glutamate in the intestine.

Glutamate is an important metabolic link between the tricarboxylic acid (TCA) cycle and urea cycle involved in cellular energy generation and nitrogen disposal [29] (Figure 9). Dietary GLU and AKG are transported from the gut lumen into the enterocyte by the excitatory amino acid carrier-1 (EAAC-1) and Na-dicarboxylate cotransporter-1 (NaDC-1) transporters respectively. Within the enterocyte, both GLU and AKG can undergo transamination and transport into the mitochondria for oxidative metabolism to $\mathrm{CO}_{2}$ [29].

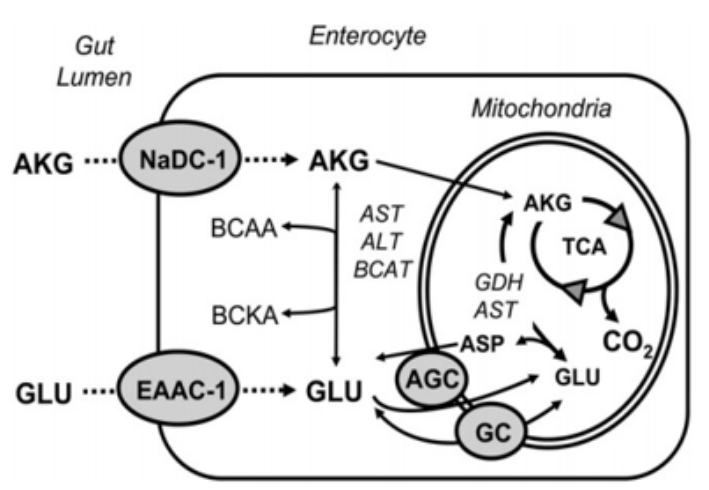

Figure 9: Metabolic fate of Dietary Glutamate (GLU) and a-Ketoglutarate $(A K G)$ in the intestinal enterocyte.
A longstanding concern with dietary glutamate consumption, particularly monosodium glutamate (MSG), is the evidence and potential risk of neurotoxicity [29]. Some have raised serious concerns about the potential risk of dietary MSG, parenteral glutamate, and its implications for human diseases, such as obesity $[28,31]$. However, it is critically important to recognize that the evidence of neurotoxicity in several experimental models only occurred with extremely high enteral and parenteral glutamate loads [15].

Glutamate, like other constituent amino acids ingested in dietary protein, is normally absorbed and metabolized in the small intestine subsequent to proteolytic digestion. However, some amino acids, especially dietary MSG, are ingested in a free form and thus may be metabolized differently when they are presented to the epithelial mucosa of the stomach [29].

\section{Effects of MSG}

Glutamate receptors are synaptic receptors that are located on the membranes of neuronal cells [33]. They play a central role in excitotoxicity and are implicated in several neurological diseases. Prevalence in the central nervous system, it has been linked to many neurodegenerative diseases, and several other conditions have been further linked to glutamate receptor gene mutations or receptor autoantigen/antibody activity [33].

Excitotoxicity is a process of overstimulation of glutamate receptors which can lead to neuronal damage and neurodegeneration. This process is carried out by excitotoxins. Excitotoxins are amino acids such as glutamate, aspartate and cysteine which when applied to neurons will cause them to be over stimulated and die. Unlike glutamic acid-containing proteins in foods, glutamate is absorbed very quickly in the gastrointestinal tract (GIT). Absorbed glutamate could spike blood plasma levels of glutamate [34]. Its concentrations in plasma are $50-100 \mu \mathrm{mol} / \mathrm{L}$, in whole brain are 10,000-12,000 $\mu \mathrm{mol} / \mathrm{L}$ but only $0.5-2 \mu \mathrm{mol} / \mathrm{L}$ in extracellular fluids (ECFs). The low ECF concentrations, which are essential for optimal brain function, are maintained by neurons, astrocytes, and the blood-brain barrier (BBB) [34].

\section{Central nervous system (CNS)}

Glutamate is the excitatory neurotransmitter in the mammalian central nervous system (CNS) playing an important role in both physiological and pathological processes [34]. Glutamate receptors include three families of ionotropic receptors (N-methyl-Daspartate, $\alpha$-amino-3-hydroxy-5-methyl-4-isoxazolepropionic acid and kainate) and three groups of metabotropic receptors (mGluR) [35]. They are dispersed throughout the central nervous system including amygdala, hippocampus and hypothalamus where they regulate many vital metabolic and autonomic functions [36]. In the brain, glutamate serves as a neurotransmitter in addition to its general role in protein and energy metabolism.

Neurotransmitters are stored in nerve endings and are used by nerve cells to inhibit or excite other nerve cells or target cells, such as muscle or endocrine cells. Concerns were raised in the late 
1960s that high doses of MSG may adversely affect brain function. The possibility of MSG-induced brain lesions through injection or force-feeding methods in rodents was also reported. The very high concentration of glutamate in the cytosol and glutamate-containing vesicles requires strict homeostatic mechanisms for the following reason. Glutamate is the major excitatory neurotransmitter, yet levels of glutamate in the extracellular fluid must be kept low $(<100$ $\mu \mathrm{M})$ to avoid excitotoxicity. In fact, the concentration of glutamate in the ambient extracellular fluid of the brain is normally $0.5-5 \mu \mathrm{M}$ [37]. This remarkable glutamate concentration gradient between the extracellular fluid and nerve cell cytosol is accomplished by powerful uptake systems for glutamate in neurons, astrocytes and synaptosomal vesicles [38].

\section{Obesity}

Data from animal studies, in which neonatal administration of MSG provides a model of obesity with impaired glucose tolerance and insulin resistance led to concerns about obesity in humans using
MSG in food. More hypotheses have proposed the mechanisms of MSG influence on metabolism. The potential link between MSG and obesity includes the MSG effect on energy balance by increasing palatability of food and by disrupting the hypothalamic signaling cascade of leptin action [28,39].

MSG has been reported to increase mRNA expression of interleukin-6, tumor necrosis factor-alpha, resistin and leptin in visceral adipose tissue, it increased insulin, resistin and leptin levels in serum and it also impaired glucose tolerance [40]. Through MSGs stimulation of the orosensory receptors and by improving the palatability of meals, it influences weight gain. Monosodium Glutamate (MSG) causes reduction in the secretion of growth hormones, leading to stunted growth and irreversibility in obesity, excessive weight, essentially due to accumulation of excess fats in adipose tissue [41], arising from high cholesterol levels leading to cardiovascular diseases and endocrinological disorder [42] (Figure 10).
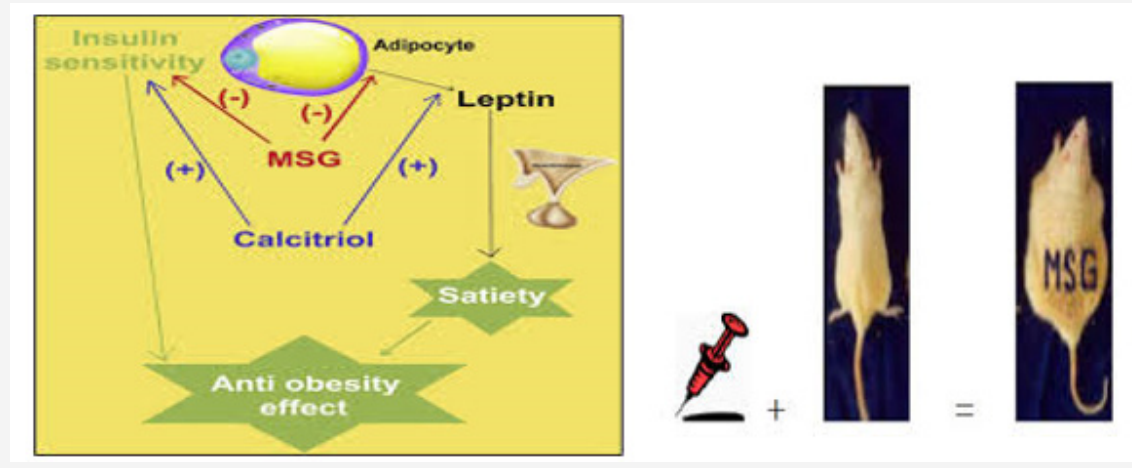

Figure 10: Induction of Weight Gain by MSG.

\section{Reproductive System}

Testosterone is a hormone in the group of androgens which directly stimulates spermatogenesis through androgen receptors located in the testis [43]. The rate or level of spermatogenesis also affects testosterone level and other reproductive hormones. Progesterone is a female sex hormone, synthesized from pregnenolone which in turn is derived from cholesterol. It is among the group of steroid hormones called progestogens. It plays a central role in ovulation, pregnancy, implantation and regulation of uterine functions [44]. Estrogens are steroid hormones produced primarily by the ovaries (the granulosa cells of the ovarian follicles and corpora lutea) and placenta (during pregnancy). The ovarian synthesis of estrogen is stimulated by Follicle-stimulating hormone (FSH) [33]. MSG has toxic effects on the testis by causing a significant oligozoospermia and increase abnormal sperm morphology in a dose dependent fashion in male wistar rats [45]. It has been implicated in male infertility by causing testicular hemorrhage, degeneration and alteration of sperm cell population and morphology [46].

\section{Hepatotoxicity}

Liver is the largest gland in the mammalian body. The hepatocytes have metabolic functions that deals with very essential processes of such a detoxification, deamination, transamination, removal of ammonia in the form of urea, biosynthesis and release of non-essential amino acids and plasma proteins with the exception of immuno gamma globulins, gluconeogenesis, storage of glycogen, conversion of carbohydrates and proteins to lipids, synthesis of lipoproteins, phospholipids and cholesterol, oxidation of fatty acids, storage of iron in the form of ferritin as well as storage of vitamins $\mathrm{A}, \mathrm{D}$ and $\mathrm{B}_{12}$. Several function tests have been formulated to explore hepatic status [47-50]. Several enzymes have been determined to explore hepatic status such as alanine aminotransferase (ALT) and aspartate aminotransferase (AST). In addition, some other tests have include measurement of serum lactic dehydrogenase (LDH), Gamma glutamyl transpeptidase (GGT), Alkaline phosphatases and 5-nucleotidase activities are employed [51-53]. The use of this substance as a flavor enhancer over time has been reported to be hepatotoxic [7].

\section{Nephrotoxicity}

Animal studies suggest that chronic monosodium glutamate intake induces kidney damage by oxidative stress [54]. Oxidative stress is caused by the excessive production or a decreased elimination of free radicals in cells, the majority of which are oxygen radicals and other reactive oxygen species (ROS) [55]. However, 
the underlying mechanisms are still unclear, despite the growing evidence and consensus that $\alpha$-ketogluterate dehydrogenase, glutamate receptors and cysteine-glutamate antiporter play an important role in up-regulation of oxidative stress in MSGinduced renal toxicity [55]. Nutrition metabolism and several extracellular and intracellular factors such as hormones, cytokines, and detoxification processes contribute to oxidative stress [56,57]. Therefore, excessive renal metabolism of glutamate in chronic MSG intake can be a source of ROS. Decreased level of major antioxidant enzymes and increased lipid peroxidation has been demonstrated in the kidney of chronic MSG-exposed rats [58]. Also, high doses of glutamate have been shown to induce significant toxicity in renal culture cells [59].

The formation of ROS in the kidney of animals exposed to MSG was a major contributor to their nephrotoxic effect leading to cellular and functional damage [60]. Paul et al. [58] found reduced activities of superoxide dismutase, catalase, glutathione-S-transferase and glutathione (GSH) in the kidney of animals after MSG administration [58]. They also reported that markers for lipid peroxidation such as malondialdehyde (MDA) and conjugated dienes were increased in MSG-treated renal tissue. It is possible that MSG leads to the excessive production of free radicals and endogenous antioxidants are insufficient to meet the demand. Moreover, some studies have found the ameliorating effects of vitamin C, E and qiercetin on MSGtreated kidneys [58]. The mechanisms whereby these antioxidants exert such effects are yet to be fully elucidated. However, these antioxidants do seem to play a key role against renal inflammatory responses through a diminution of the activity of inflammatory enzymes and cytokines secretion, or by inhibiting the activity of NF-KB [61].

\section{Prevention of MSG Toxic Effects}

Consumption of MSG between 0.3 and 1 gram daily has been reported to be safe. However, in studies involving mice, this has varied according to weight. Consumer protection agencies advise healthy persons to avoid consuming MSG frequently. The following has been reported to minimize the toxic effect of MSG.

\section{Frequent intake of Vitamin C}

MSG has been reported to be toxic, especially the nervous tissues. It causes cellular death through oxidative stress [61]. With the known benefits of vitamin $\mathrm{C}$, it can reduce the adverse effect of MSG. Research has shown that vitamin C is an antioxidant, with the ability to clean up free radicals produced in the body [62]. Vitamin C can scavenge superoxide, hydrogen peroxide and hydroxyl radicals. Vitamin C has been reported to reverse the impact of MSG on the liver by causing a significant drop in the unhealthy growth cells and reducing mutations of tumor suppressor genes [63]. It has also been reported to have a protective effect on the liver [64].

\section{Vitamin E}

Vitamin E is an important component of the human diet. It exerts protective effects against diseases which may be attributed to its powerful antioxidant property [8]. As an antioxidant, it protects against the damaging effects of free radicals, which may contribute to the development of diseases [63]. Research has shown that MSG induces oxidative stress and Vitamin E significantly reduces the oxidative stress. In mammals, it has been reported to stabilize the membrane and scavenges lipid peroxy radicals and singlet oxygen [64].

\section{Garlic}

Garlic is a species of the onion family called Allium sativum. It is in antioxidants, thus its numerous health benefits. Garlic also contains enzymes, calcium, copper, iron, manganese, phosphorus, potassium and selenium. Vitamins in garlic include vitamin A, vitamin $\mathrm{B}_{1}$ (thiamine), vitamin $\mathrm{B}_{2}$ (riboflavin), vitamin $\mathrm{B}_{6}$ and vitamin C [63].

\section{Curcuma longa (Tumeric)}

Curcuma longa commonly referred to as turmeric is a rhizomatous herbaceous perennial plant of the ginger family, Zingiberaceae [65]. Curcuma longa has been used in traditional remedy for a wide range of ailments, including wound healing, urinary and gastrointestinal tract infections, and liver ailments [66]. Curcumin has been defined as the most active component in Curcuma longa and has been shown to have considerable gastroprotective, anti-ulcerogenic and therapeutic effect in gastric ulcer disease [66]. Report by Airaodion et al. [67] showed that turmeric is potent in the prevention of peptic ulcer due to the presence of flavonoid and other antioxidants. Due to its content stated above, turmeric has the propensity to annul the effect of MSG on the body.

\section{Ginger}

Ginger (Zingiber officinale) is used as spice in food and beverages and in traditional medicine as carminative, antipyretic and in the treatment of pain, rheumatism and bronchitis [68]. Its extracts have been extensively studied for a broad range of biological activities including antibacterial [69], analgesic and anti-inflammatory [70], antiangiogenesis and antitumor. It has also been used for the treatment of gastrointestinal disorders including gastric ulcerogenesis [71]. Ginger has also been reported to be potent in the prevention of peptic ulcer owing to its flavonoid and antioxidant properties [72]. With these biological activities, ginger has the ability to minimize the effect of MSG on human health.

\section{Locust beans}

Locust bean (Parkia biglobosa) is used as a condiment in cooking. It is very popular in among the Yoruba people of Nigeria where it is called 'iru'. It can be fresh or dried. Dried locust bean is weaker in flavor and pungency than fresh. Locust bean is high in lipids (29\%), Proteins (35\%), and carbohydrates (16\%). It is a good source of calcium and fat for rural dwellers. During fermentation, the reducing sugar content increases, and the total free amino acid content initially decreases [73]. Locust beans can conveniently be used instead of MSG-containing seasonings. 


\section{Conclusion}

This study demonstrated that monosodium glutamate is hazardous to the human health as it is linked to Chinese Restaurant Syndrome (CRS). Regular intake of MSG for a long period of time can lead to conditions such as hepatotoxicity, renal damage, Fibroid, Obesity etc. More awareness concerning the hazardous effects of MSG should be created to enlighten people and natural alternatives for MSG should be promoted.

\section{Conflict of Interest}

No conflict of interest.

\section{Acknowledgement}

None.

\section{References}

1. Guyton A, Hall J (1996) Textbook of Medical Physiology. WB Saunders Co Philadelphia, Pennsylvania.

2. David Tin Win (2008) MSG-Flavor Enhancer or Deadly Killer. AU J T 12(1): 43-49.

3. Chaudhari N, Landin AM, Roper SA (2000) Metabotropic glutamate receptor variant functions as a taste receptor. Nat Neurosci 3(2):113119.

4. Kurihara K (2015) Umami the Fifth Basic Taste: History of Studies on Receptor Mechanisms and Role as a Food Flavor. BioMed Research International 189402: 1-10.

5. Meraiyebu A, Akintayo CO, Uzoechi AC, Okere S (2012) The Effects of Orally Administered Monosodium Glutamate (MSG) on Blood Thrombocyte, Blood Coagulation and Bleeding in Rats. IOSR Journal of Pharmacy and Biological Sciences (IOSR-JPBS) 4(1): 04-08.

6. Obochi GO, Malu SP, Obi Abang M, Alozie Y, Iyam MA (2009) Effect of Garlic Extracts on Monosodium Glutamate (MSG) Induced Fibroid in Wistar Rats. Pakistan Journal of Nutrition 8 (7): 970-976.

7. Egbuonu ACC, Obidoa O, Ezeokonkwo CA, Ezeanyika LUS, Ejikeme PM (2009) Hepatotoxic effects of low dose oral administration of monosodium glutamate in male albino rats. African Journal of Biotechnology 8 (13): 3031-3035.

8. Onyema OO, Farombi EO, Emerole GO, Ukoha AI, Onyeze GO (2006) Effect of vitamin $\mathrm{E}$ on monosodium glutamate induced hepatotoxicity and oxidative stress in rats. Indian J Biochem Biophys 43: 20-24.

9. Meraiyebu A, Akintayo CO, Uzoechi AC, Okere S (2012) The Effects of Orally Administered Monosodium Glutamate (MSG) on Blood Thrombocyte, Blood Coagulation and Bleeding in Rats. IOSR Journal of Pharmacy and Biological Sciences (IOSR-JPBS) 4(1): 04-08.

10. Onyema OO, Alisi CS, Ihetuge AP (2012) Monosodium Glutamate Induces Oxidative Stress and Affects Glucose Metabolism in the Kidney of Rats. International Journal of Biochemistry Research \& Review 2(1): 1-11.

11. Nwajei J C, Onuoha SC, Essien EB (2015) Effects of Oral Administration of Selected Food Seasonings Consumed in Nigeria on Some Sex Hormones of Wistar Albino Rats. IOSR Journal of Biotechnology and Biochemistry (IOSR-JBB) 1(5): 15-21.

12. Kolawole OT (2013) Assessment of the effects of monosodium glutamate on some biochemical and hematological parameters in adult wistar rats. American Journal of BioScience 1(1): 11-15.

13. Nakamura Jun, Wachi Masaaki (2008) Mechanism of L-Glutamic Acid Fermentation by Corynebacterium Glutamicum. Foods Food Ingredients J Jpn. 213(12): 1.

14. Ganong W (1999) Review of Medical Physiology, Appleton and Lange, Stamford.

15. Thomas M, Sujatha KS, George S (2009) Protective effect of piper longum Linn. on monosodium glutamate induced oxidative stress in rats. Indian J Exp Biol 47(3): 186-192.
16. Farombi EO, Onyema OO (2006) Monosodium glutamate-induced oxidative damage and genotoxicity Sin the rat: modulatory role of Vitamin C, Vitamin E and quercetin. Hum Exp Toxicol 25(5): 251-259.

17. Andersen JK (2004) Oxidative stress in neurodegeneration: cause or consequence. Nat Med 10(suppl): 518-525.

18. Grossman E, Messerli FH (2004) Calcium antagonists. Prog Cardiovasc Dis $47(1): 34-57$.

19. Nelson G, Chandrashekar J, Hoon MA, Feng L, Zhao G (2002) An amino acid taste receptor. Nature 416: 199-202.

20. Price A, Lucas PW, Lea PJ (1990) Age dependent damage and glutathione metabolism in ozone fumigated barley: a leaf section approach. J Exptl Bot 41: 1309-1317.

21. Macarthur R, Crews C, Davies A, Brereton P, Hough P, et al. (2000) 3-monochloropropane-1, 2-diol (3-MCPD) in soy sauces and similar products available from retail outlets in the UK. Food addit contam 17(11): 903-906.

22. Cobley L (2002) Stimulants in food seasoning. Encyclopaedia Americana 17: $15-30$.

23. Nayanatara AK, Vinodini, NA, Damodar G, Ahemed B, Rameshwamy CR, et al. (2008) Role of ascorbic acid in monosodium glutamate mediated effect on testicular weight, sperm morphology and sperm count, in rat testis. J Chin Clin Med 3(1): 1-5.

24. Airaodion AI, Ogbuagu U, Oloruntoba AP, Agunbiade AP, Airaodion EO, et al. (2019) Biochemical Mechanisms Involved in the Regulation of Appetite and Weight-Review. International Journal of Research 6(2): 397-409.

25. (1968) Chinese Restaurant Syndrome. Can Med Assoc J 99(24): 12061207.

26. Geha R S, Beiser A, Ren C, Patterson R, Greenberger PA, et al. (2000) Review of Alleged Reaction to Monosodium Glutamate and Outcome of a Multicenter Double-Blind Placebo-Controlled Study. J Nutr 130 (4S Suppl), 1058S-1062S.

27. Zautcke J L, Schwartz J A, Mueller E J (1986) Chinese Restaurant Syndrome: A Review. Annals of Emergency Medicine 15 (10): 12101213.

28. Hermanussen M, Tresguerres J A F (2003) Does High Glutamate Intake Cause Obesity? J Pediatr Endocrinol Metab 16(7): 965-968.

29. Burrin GD, Stoll B (2009) Metabolic fate and function of dietary glutamate in the gut. Am J Clin Nutr 90(suppl): 850S-856S.

30. Fan M Z, Matthews J C, Etienne NM, Stoll B, Lackeyram D, et al. (2004) Expression of apical membrane L-glutamate transporters in neonatal porcine epithelial cells along the small intestinal crypt-villus axis. Am J Physiol Gastrointest Liver Physiol 287: G385-G398.

31. Kirchgessner AL (2001) Glutamate in the enteric nervous system. Curr Opin Pharmacol 1(6): 591-596.

32. Iwanaga T, Goto M, Watanabe M (2005) Cellular distribution of glutamate transporters in the gastrointestinal tract of mice: an immunohistochemical and in situ hybridization approach. Biomed Res 26: $271-278$.

33. Nelson LR, Bulun SE (2001) Estrogen production and action. J Am Acad Dermatol 45 (3): 116-124.

34. Meldrum B (1993) Amino acids as dietary excitotoxins: a contribution to understanding neurodengerative disorder. Brain Res Brain Res Rev 18: 293-314.

35. Mattson M P (2008) Glutamate and Neurotrophic Factors in Neuronal Plasticity and Disease. Ann N Y Acad Sci 1144: 97-112.

36. Collison K S, Makhoul N J, Zaidi M Z, Al Rabiah R, Inglis A, et al. (2012) Interactive Effects of Neonatal Exposure to Monosodium Glutamate and Aspartame on Glucose Homeostasis. Nutr Metab (Lond) 9(1): 58.

37. Featherstone DE, Shippy SA (2008) Regulation of synaptic transmission by ambient extracellular glutamate. Neuroscientist 14: 171-181.

38. Zhou Y, Danbolt NC (2014) Glutamate as a neurotransmitter in the healthy brain. J Neural Transm 121: 799-817. 
39. He K, Du S, Xun P, Sharma S, Wang H, et al. (2011) Consumption of Monosodium Glutamate in Relation to Incidence of Overweight in Chinese Adults: China Health and Nutrition Survey (CHNS). Am J Clin Nutr 93(6): 1328-1336.

40. Roman Ramos R, Almanza Perez J C, Garcia Macedo R, Blancas Flores G, Fortis Barrera A, et al. (2011) Monosodium Glutamate Neonatal Intoxication Associated with Obesity in Adult Stage is Characterized by Chronic Inflammation and Increased mRNA Expression of Peroxisome Proliferator-Activated Receptors in Mice. Basic Clin Pharmacol Toxicol 108(6): 406-413.

41. Ikonomidou C, Turski L (1995) Glutamate in neurodegenerative disorders. Neurotransmitters Neuromodulators: Glutamate. CRC Press Boca Raton 17: 253-272.

42. Eskes TK (1998) Neutral tubes defects, vitamins and homocysteine. Eur J Pediatr 157: 5139-5141.

43. Wang RS, Yeh C, Tzeng CC (2009) Androgen receptor roles in spermatogenesis and fertility: Lessons from testicular cell specific androgen receptor knockout mice. Endocr Rev 30(2): 119-132.

44. Maha A (2007) Reproductive Functions of Progesterone. Journal of Middle East Fertility Society 12(3): 1-6.

45. Onakewhor JUE, Oforofuo IAO, Singh SP (1998) Chronic administration of Monosodium glutamate induces Oligozoospermia and glycogen administration in Wistar rat testes. Africa Journal of Reproduction and Health 2(2): 190-197.

46. Oforofuo IAO, Onakewhor JUE, Idaewor PE (1997) The effects of chronic administration of MSG on the Adult Wistar rat testes. Journal of Bioscience Research 9(2): 6-15.

47. Johnson P (1995) The Assessment of Hepatic Function and Investigation of Jaundice. In: Marshall W, Bangert S (Eds.). Clinical Biochemistry: Metabolic and Clinical Aspects. Churchill Livingstone. New York, USA, pp: 217-236.

48. Stryer L (1995) Biochemistry WH Freeman and Company, New York, USA.

49. Nelson D, Cox M (2000) Lehninger Principles of Biochemistry. Worth Publishers, New York, USA

50. Owoade AO, Airaodion AI, Adetutu A, Akinyomi OD (2018) Levofloxacin induced dyslipidemia in male albino rats. Asian Journal of Pharmacy and Pharmacology 4(5): 620-629.

51. Gowenlock A, McMurray J, McLauchlan D (1998) Varley’s Practical Clinical Biochemistry, Redwood Burn Ltd, Wiltshire, UK.

52. Montgomery T, Conway T, Spector A (1990) Biochemistry: A Case Oriented Approach, The CV Mosby Company, St. Louis, USA.

53. Burtis C, Ashwood E (1999) Tietz Textbook of Clinical Chemistry, WB Saunders Company, London, UK.

54. Sharma A (2015) Monosodium glutamate-induced oxidative kidney damage and possible mechanisms: a mini-review. Journal of Biomedical Science 22: 93.

55. Bashan N, Kovsan J, Kachko I, Ovadia H, Rudich A (2009) Positive and negative regulation of insulin signaling by reactive oxygen and nitrogen species. Physiol Rev 89(1): 27-71.

56. Corda S, Laplace C, Vicaut E, Duranteau J (2001) Rapid reaction oxygen species production by mitochondria in endothelial cells exposed to tumor necrosis factor-alpha is mediated by ceramide. Am J Repair Cell Mol Biol 24(6): 762-768.
57. Stankiewicz A, Skrzydlewska E, Makiela M (2002) Effects of amifostine on liver oxidative stress caused by cyclophosphamide administration to rats. Drug Metabol Drug Interact 19(2): 67-82.

58. Paul MV, Abhilash M, Varghese MV, Alex M, Nair RH (2012) Protective effects of alpha-tocopherol against oxidative stress related to nephrotoxicity by monosodium glutamate in rats. Toxicol Mech Methods 22(8): 625-630.

59. Leung JC, Ragland N, Marphis T, Silverstein DM (2008) NMDA agonists and antagonists induce renal culture cell toxicity. Med Chem 4(6): 565571.

60. Ortiz GG, Bitzer Quintero OK, Zarate CB, Rodriguez Reynoso S, Larios Arceo F, et al. (2006) Monosodium glutamate-induced damage in the liver and kidney: a morphological and biochemical approach. Biomed Pharmacother 60(2): 86-91.

61. Ozaki M, Yamanda Y, Matoba K, Otani H, Mune M, et al. (1999) Phospholipase A2 activity in ox-LDL- stimulated mesengial cells and modulation by alpha-tocopherol. Kidney Int Suppl 71: S171-S173.

62. Airaodion AI, Olatoyinbo PO, Ogbuagu U, Ogbuagu EO, Akinmolayan JD, et al. (2019) Comparative Assessment of Phytochemical Content and Antioxidant Potential of Azadirachta indica and Parquetina nigrescens Leaves. Asian Plant Research Journal 2(3): 1-14.

63. Eweka AO, Eweka A, Om'Iniabohs FAE (2010) Histological studies of the effects of monosodium glutamate on the fallopian tube of adult female Wistar rats. N Am J Med Sci 2(3):146-149.

64. Chiaki Sano (2009) History of Glutamate Production. Am J Clin Nutr $90(3)$ : 7285-7325.

65. Priyadarsini KI (2014) The chemistry of curcumin: from extraction to therapeutic agent. Molecules 19(12): 20091-20112.

66. Kim DC, Kim SH, Kim D, Kim MJ (2005) Curcuma longa extract protects against gastric ulcers by blocking $\mathrm{H} 2$ histamine receptors. Biol Pharm Bull 28(12): 2220-2224.

67. Airaodion AI, Obajimi OO, Ezebuiro CN, Ogbuagu U, Agunbiade AP, et al. (2019) Prophylactic Efficacy of Aqueous Extract of Curcuma longa Leaf Against Indomethacin-Induced Ulcer. International Journal of Research 6(1): 87-91.

68. Afzal M, Al Hadidi, Menon M, Pesek J, Dhami MS (2001) Ginger: an ethnomedicinal, chemical and pharmacological review. Drug Methabol Drug Interac 18(3-4): 159-190.

69. Mahady GB, Pendland SL, Yun GS, Lu ZZ, Stoia A (2003) Ginger (Zingiber officinale Roscoe) and the gingerols inhibit the growth of Cag A' strains of Helicobacter pylori. Anticancer Res 23(5A): 3699-3702.

70. Grzanna R, Linmark L, Frondoza CG (2005) Ginger-an herbal medicine product with broad anti-inflammatory actions. J Med Food 8(2): 125132.

71. Moshen M, Alireza G, Alireza K (2006) Anti-ulcerogenic effect of ginger (rhizome of Zingiber officinale Roscoe) on cystemine induced duodenal ulcer in rats. DARU 14: 97-101.

72. Airaodion AI, Ogbuagu U, Ogbuagu EO, Airaodion EO, Agunbiade AP, et al. (2019) Investigation of Aqueous Extract of Zingiber officinale Root Potential in the Prevention of Peptic Ulcer in Albino Rats. International Journal of Research and Innovation in Applied Science 4(2): 64-67.

73. Abaelu AM, Olukoya DK, Okochi VI, Akinrisimi EO (1990) Biochemical changes in fermented melon (egusi) seeds (Citrullis vulgaris). Journal of Industrial Microbiology 6(3): 211-214. 